\title{
Disability Rights and Management in Pakistan: Time to Face the Bitter Truth
}

\author{
Faroog Azam Rathore 1 and Sahibzada Nasir Mansoor ${ }^{2}$ \\ IDepartment of Rehabilitation Medicine, PNS Shifa Hospital, Karachi, Pakistan \\ 2Department of Rehabilitation Medicine, Armed Forces Institute of Rehabilitation Medicine, Abid Majeed Road, Rawalpindi, Pakistan
}

According to the 6th Population and Housing Census of 2017, the population of Pakistan is around 207 million. 1 Considering the World Health Organization (WHO) estimate of 15 percent prevalence of global disability, ${ }^{2}$ around 31 million people in Pakistan are expected to be living with some form of disability. But there are no reliable statistics on disability in Pakistan. ${ }^{3}$ So far, there has been no large-scale national survey to document the true burden of disability in Pakistan. The last national census to document disability was conducted in 1998.

The $3^{\text {rd }}$ of December is being celebrated as the International Day of Persons with Disabilities (PWD) all around the Globe since 1992. ${ }^{3}$ The usual routine on this day is limited to either a seminar or walk on the theme of disability. So far, these activities have not brought a grassroot level change in the lives of PWD, or improved the perception about disability in Pakistan.

PWD in Pakistan are largely isolated and living in shadows; and are not seen participating actively in the society along with the able-bodied members of the society. This isolation of PWD in Pakistan is multifactorial. Disability is still considered a stigma in our society. ${ }^{4}$ Sometimes, it is even considered a punishment for the sins and ill-doings and a source of shame for the family. People are uncomfortable in moving in the society with a child having a physical or mental disability. Those who overcome the societal barriers and attempt to integrate into the society, face mobility barriers. Majority of the buildings, educational institutes, and religious places in Pakistan do not cater to the needs of PWD who have mobility dysfunction; except for a few public and private buildings and shopping malls constructed in the last decade. A ramp may significantly improve the mobility of a PWD using wheelchair, but it is nowhere to be seen. In places where ramps are available, the gradients are so steep that these become practically impossible to use. Mosques have a pivotal role in the social life of a Muslim-majority country, like Pakistan. They are not only the place for worship, but

Correspondence to: Dr. Farooq Azam Rathore, Department of Rehabilitation Medicine, PNS Shifa Hospital, Karachi, Pakistan E-mail: farooqrathore@gmail.com

Received: October 16, 2019; Revised: December 5, 2019;

Accepted: December 5, 2019 also for social gathering where people get to know each other and make long-lasting connections. In our clinical practice, we came across many patients who stopped going to mosques after suffering from a disability due to mobility and social barriers. It is very frustrating for a person, who for decades went to the mosque regularly, only to be excluded from that activity because of lack of a simple thing like a ramp or being ashamed of being seen in public on a wheelchair.

Parents of children with a disability described that their children were flatly denied admission in elite schools just because the child had mobility issues despite the medical certificate that the child had no intellectual limitation and will be able to perform at par with the ablebodied children without disability. Parents of children with physical disability but normal IQ have been told to take their children to special schools for the disabled. This attitude is not only discriminatory, but indicates a hollow and biased mindset which is unable to identify and nurture the true potential of PWD.

The lack of understanding of the unique issues and dimensions of PWD is also a problem with most of the healthcare professionals in Pakistan. Patients having children with disability, especially cerebral palsy spectrum and neurodegenerative disorders, are inadequately counselled by junior doctors usually and told that they are not going to become "normal" again. They are prescribed a cocktail of multi-vitamins, neurotronics, and other herbal medicines for years instead of identifying and managing their issues related to disability. This results in complications like contractures, muscle wasting, cognitive decline, reduced mobility, pain, and a poor quality of life both for the child and the parents.

There are more than 50 clinical specialties accredited for Membership and Fellowship training by the College of Physicians and Surgeons of Pakistan (CPSP). ${ }^{5}$ Apart from physical medicine and rehabilitation, none of the specialties has any dedicated module or training in the assessment and management of disabilities. There is a need to seriously address the complex issue of disability in Pakistan. It requires input from multiple stakeholders including the PWD, governmental organisations, nongovernmental organisations (NGOs), international bodies like WHO, media, medical societies and health-care professionals from different disciplines. 
The foremost step should be to document the national burden of disability by designing and conducting a national disability survey. The 1998 census estimates of 3.2 million PWD in Pakistan are totally outdated and not accurate. ${ }^{6}$ The survey must have physicians involved in the management of disability (rehabilitation medicine physicians, neurologists, pediatricians and neurosurgeons). It should document the epidemiological pattern of disability in a scientific manner instead of categorising it into vague categories like blind, mute, crippled, deaf, insane, mentally retarded, and having multiple disabilities (1998 census). ${ }^{6}$ In case a national survey is not a possibility, large scale countrywide hospital-based collection of data on disability should be taken into account. Major hospitals in big cities should be involved in data collection. Data should be geographically representative of the Pakistani population instead of focusing on only few major centres.

The current undergraduate medical curriculum in Pakistan does not have disability studies. A module or series of lecture programme on disability assessment and management must be introduced at the undergraduate medical curriculum by the statutory council. This will increase the awareness about disability in the future physicians of the country. CPSP must also introduce assessment and management of different forms of major physical disabilities for different clinical specialties tailored to their practice as a mandatory module. It will enhance understanding of the principles of assessment and management of different forms of disabilities in their clinical practice.

Rehabilitation professionals in Pakistan (rehabilitation medicine physicians, physiotherapists, occupational therapists, clinical psychologists and orthotists) are working mostly in isolation and are unable to provide comprehensive services to PWD due to professional limitations and lack of a multi-disciplinary team approach. ${ }^{7}$ It is important that rehabilitation professionals should respect each others' domains and adopt a multidisciplinary team-approach instead of providing individual and isolated rehabilitation interventions. The allied professionals like physiotherapists, occupational therapists, prosthetists and speech therapist, should be registered as practitioners. Their training must be registrable, to avoid burden on the families for providing inadequate services.

The government should enforce the disability legislations. Mobility barriers should be reduced and public places must be made accessible for PWD. Discrimination against PWD must be addressed and they should be facilitated for community re-integration. Equal educational opportunities should be provided and ensured for children with disabilities.

The NGOs and organisations working in the field of disability management should have better coordination and data sharing to avoid duplication of efforts and to improve the quality of services for a better life for PWD in Pakistan. Media should also be more proactive in promoting PWD as a possible role-model and to highlight that they can live a normal and fulfilling life. The success stories of PWD should be shared more often and advocacy against social discrimination towards PWD.

\section{REFERENCES}

1. Pakistan Bureau of Statistics. Population Census. Available from http://www.pbs.gov.pk/content/population-census [Accessed on 7th October 2019].

2. World Bank. World report on disability: Main report (English). Washington, DC: World Bank. 2011 Available from http:// documents.worldbank.org/curated/en/665131468331271288/ Main-report [Accessed on 7th October 2019].

3. United Nations. International Day of Persons with Disabilities 3 December. Background. Available from https://www.un.org/ en/events/disabilitiesday/ [Accessed on 7th Oct 2019].

4. Rathore FA, New PW, Iftikhar A. A report on disability and rehabilitation medicine in Pakistan: Past, present, and future directions. Arch Phys Med Rehabil 2011; 92:161-6.

5. College of Physicians and Surgeons Pakistan. Fellowship of the College of Physicians and Surgeons - FCPS. Available from https://www.cpsp.edu.pk/fcps.php [Accessed on 7th Oct 2019].

6. Pakistan Bureau of Statistics. Population Census.1.16 Disabled population by nature of disability. Available from http://www. pbs.gov.pk/sites/default/files//tables/DISABLED\%20POPULAT ION\%20BY\%20NATURE \%200F\%20DISABILITY.pdf [Accessed on 7th October 2019].

7. Rathore FA, Wasay M. Acute stroke care and long-term rehabilitation in Pakistan: Challenges and solutions. J Pak Med Assoc 2016; 66:1203-4. 